\title{
The Janus in the Soviet Camp
}

THAT science and politics are inextricably mixed in the Soviet Union is well known, especially to those who have regularly followed the pages of Nature in recent years. But in the past twelve months there has been evidence of an increased thaw in relations between the Soviet Union and the western world and it is sad that yet once again an event has occurred which is bound to set back the processes by which amiable interchanges between the Soviet Union and the West have increased.

The incident which has now cropped up concerns the treatment accorded Dr Evgeny Levich, son of Professor Benjamin Levich, and if all the details which have emerged from the Soviet Union are substantiated, it represents a complete reversal to all that was bad in the Stalinist era. Evgeny, whose trials began in March 1972 when he applied for permission to emigrate to Israel, has recently been whisked away to Tiksi within the Arctic circle to start a period of military service. But the unsavoury aspect of the entire affair is the way in which this was done without any apparent regard for Evgeny's medical condition. A year ago (see Nature, 238,$365 ; 1972$ ) it was reported that he had a serious blood pressure condition but according to a recent telephone message from Professor Benjamin Levich his son's condition has now been diagnosed as being caused by ulcerous colitis and multiple diverticulosis of the bowels. As if this is not enough Evgeny is also reported to have a rectal tumour whose nature has yet to be described. This then was the condition of the young Levich when on May 16 he was apprehended on the street by what can only be described as a press gang which took him away leaving his wife helplessly behind.

But what can now be done? Professor Levich hopes that by means of a massive outcry from the scientific community outside the Soviet Union the authorities will be forced to return his son from Siberia to Moscow both to receive further medical treatment and to continue his work as an astrophysicist at the Chemical Physics Institute of the Academy of Sciences. But it must be asked whether this is a pious hope? Professor Levich himself feels that his position has been bettered within the Soviet Union following just such a campaign which was launched a year ago on his behalf when he was deprived of his university chair and of his position as head of the Institute of Electrochemistry in Moscow following his application-along with his sons - for permission to emigrate to Israel. It is true that recently Professor Levich's right to publish in the open literature has been restored but now there is news that he is faced with expulsion from the Soviet Academy of Sciences, on the grounds that he had engaged in activities harmful to the Soviet Union. These activities, apparently, were his refusal to protest against the efforts being made in Britain and elsewhere to publicize his case. These included a press conference called last summer by scientists who had met Professor Levich in Moscow and an appeal launched on his behalf by Professor D. B. Spalding of Imperial College. Professor Levich, however, has had neither his chair nor his position as head of the Institute restored since the campaign began.

In spite of this superficial lack of success, has the campaign in fact prevented Professor Levich's plight worsening? Professor Levich himself is convinced that much worse would have befallen him if it were not for the interest his case has raised outside the Soviet Union. From the position of an onlooker, in which the rest of the scientific community necessarily finds itself, it is difficult to argue with this logic. It now seems that a much better test of the sensitivity of the Soviet authorities to outside pressure will be found in the case of Evgeny Levich. Here, at least, the aim is straightforward, namely to have him certified medically unfit for military service. The campaign will have been a success if Evgeny is indeed returned to Moscow for treatment and to resume his career.

But only time will tell if an all out campaign of publicity is the best way to help Evgeny Levich. What is unfortunate though is that it is highly unlikely that the many scientists working in the Soviet Union who are regular readers of this journal will have the opportunity of seeing this comment on the plight of one of their colleagues. It is only six months since Nature published proof that severe censorship of this journal takes place before it is circulated within the Soviet Union (Nature, 240, 372; 1972) and from other accounts it is an unknown occurrence for the journal to appear regularly week after week. If the Soviet authorities are really intent on making a success of the various formal and informal exchange arrangements which are now in existence between them and other countries they must show that they are willing to do away with some of the restrictions placed on the scientific community which have persisted since the days of Stalin.

\section{Years Ago}

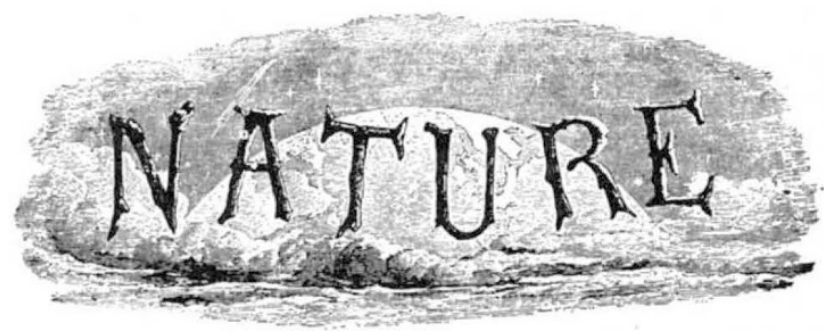

Hail Storm

DURING the passage across us this afternoon of a thunderstorm moving at so great a distance above the earth that the thunder was very feeble and the lightning very faint, we had a great hail storm, which commenced with conical-shaped opaque stones of the size of peas, at $4^{\mathrm{h}} 27^{\mathrm{m}}$ (only lasting one minute), beginning again at $4^{\mathrm{h}} 29^{\mathrm{m}}$ with circular transparent stones having a small opaque nucleus (again only lasting one minute), followed at $4^{\mathrm{h}} 33^{\mathrm{m}}$ with flattened stones of the form of common acid drops, transparent, except a thin opaque envelope (which soon melted), and having externally in the centre a small rugged piece of ice.

Highfield House Observ., Nottingham, June 3 E. J. Lowr 